\title{
Revision surgery in anterior cruciate ligament reconstruction: a cohort study of 17,682 patients from the Swedish National Knee Ligament Register
}

\author{
Neel Desai ${ }^{1,2} \cdot$ Daniel Andernord $^{2,3,4} \cdot$ David Sundemo $^{1,2} \cdot$ Eduard Alentorn-Geli $^{5}$ • \\ Volker Musahl $^{6} \cdot$ Freddie Fu $^{6} \cdot$ Magnus Forssblad $^{7} \cdot$ Kristian Samuelsson $^{1,2}$
}

Received: 7 September 2016 / Accepted: 1 December 2016 / Published online: 19 December 2016

(c) The Author(s) 2016. This article is published with open access at Springerlink.com

\begin{abstract}
Purpose To investigate the association between surgical variables and the risk of revision surgery after ACL reconstruction in the Swedish National Knee Ligament Register. Methods This cohort study was based on data from the Swedish National Knee Ligament Register. Patients who underwent primary single-bundle ACL reconstruction with hamstring tendon were included. Follow-up started with primary ACL reconstruction and ended with ACL revision surgery or on 31 December, 2014, whichever occurred first. Details on surgical technique were collected using an online questionnaire. All group comparisons were made in relation to an "anatomic" reference group, comprised of essential AARSC items, defined as utilization of accessory medial portal drilling, anatomic tunnel placement,
\end{abstract}

Neel Desai

neel@desai.nu

1 Department of Orthopedics, Sahlgrenska University Hospital, 43180 Mölndal, Sweden

2 Department of Orthopedics, Institute of Clinical Sciences, The Sahlgrenska Academy, University of Gothenburg, Gothenburg, Sweden

3 Vårdcentralen Gripen, Karlstad, Sweden

4 Primary Care Research Unit, County Council of Värmland, Karlstad, Sweden

5 Department of Orthopaedic Surgery, Mayo Clinic, Rochester, MN, USA

6 Department of Orthopedic Surgery, University of Pittsburgh, Pittsburgh, PA, USA

7 Stockholm Sports Trauma Research Center, Karolinska Institutet, Stockholm, Sweden visualization of insertion sites and pertinent landmarks. Study end-point was revision surgery.

Results A total of 108 surgeons (61.7\%) replied to the questionnaire. A total of 17,682 patients were included [ $n=10,013$ males (56.6\%) and 7669 females (43.4\%)]. The overall revision rate was $3.1 \%$. Older age as well as cartilage injury evident at index surgery was associated with a decreased risk of revision surgery. The group using transtibial drilling and non-anatomic bone tunnel placement was associated with a lower risk of revision surgery [HR 0.694 (95\% CI 0.490-0.984); $P=0.041$ ] compared with the anatomic reference group. The anatomic reference group showed no difference in risk of revision surgery compared with the transtibial drilling groups with partial anatomic [HR 0.759 (95\% CI 0.548-1.051), n.s.] and anatomic tunnel placement [HR 0.944 (95\% CI 0.718-1.241), n.s.]. The anatomic reference group showed a decreased risk of revision surgery compared with the transportal drilling group with anatomic placement [HR 1.310 (95\% CI 1.047-1.640); $P=0.018]$.

Conclusion Non-anatomic bone tunnel placement via transtibial drilling resulted in the lowest risk of revision surgery after ACL reconstruction. The risk of revision surgery increased when using transportal drilling. Performing anatomic ACL reconstruction utilizing eight selected essential items from the AARSC lowered the risk of revision surgery associated with transportal drilling and anatomic bone tunnel placement. Detailed knowledge of surgical technique using the AARSC predicts the risk of ACL revision surgery. Level of evidence III.

Keywords Anterior cruciate ligament · Revision . Register $\cdot$ Anatomic $\cdot$ Drilling $\cdot$ Reconstruction 


\section{Introduction}

Anterior cruciate ligament (ACL) reconstruction has evolved considerably over the last decades. Surgical factors such as graft selection and fixation methods, drilling techniques and subsequent tunnel placement have been of particular interest. Biomechanical and clinical studies have shown superior results with anatomic reconstruction techniques [7, 11, 12, 20, 31]. In addition, several longterm clinical trials have revealed suboptimal results when non-anatomic techniques are used [4, 5, 13, 21, 25]. Nonanatomic bone tunnel placement is often cited as the most common cause of clinical failure [10, 15, 19, 24]. A multicentre study by the MARS group revealed that in at least $50 \%$ of the revision cases, technical error was either a predominant or contributing factor [28]. Of these, malpositioning of the femoral and/or tibial tunnels were leading causes. Interestingly, several studies have recently shown that anatomically placed grafts are exposed to greater in situ forces than non-anatomically placed ones [3, 11, 16, 29], possibly reflected by results from the Danish Knee Ligament Reconstruction Register showing an increased risk of ACL revision surgery when the transportal (TP) technique was used compared with the transtibial (TT) technique [23]. In contrast, higher odds of repeat ipsilateral knee surgery have been reported in those patients undergoing ACL reconstruction using a TT technique compared with TP technique [8]. The recent introduction of the anatomic anterior cruciate ligament reconstruction scoring checklist (AARSC) provides a tool for evaluating the surgical techniques employed in ACL reconstructions. It has previously been implemented in a systematic review [6]. However, it has yet to be applied to large patient cohorts. The purpose of this population-based cohort study was to analyse data from the Swedish National Knee Ligament Register and apply the AARSC checklist in order to investigate whether detailed knowledge of surgical technique can be used to predict the risk of ACL revision surgery.

\section{Materials and methods}

Patient data were extracted from the Swedish National Knee Ligament Register. Patients registered for primary ACL reconstruction from 1 January, 2005, to 31 December, 2014 were eligible for inclusion. Only patients aged 13-49 years who underwent primary single-bundle (SB) ACL reconstruction using a hamstrings graft were included. Follow-up started on the date of primary ACL reconstruction and ended with ACL revision surgery, or on 31 December, 2014, whichever occurred first. No minimum follow-up time was pre-specified; instead patients with a possible follow-up shorter than the earliest documented event (revision ACL surgery) in the specific cohort were censored from analysis. Exclusion criteria are summarized in Fig. 1. Data on age at index surgery, patient sex, as well as data regarding graft choice and concomitant injuries noted at index surgery, were extracted from the Swedish National Knee Ligament Register. All data pertaining to surgical technique were gathered via an online questionnaire described below.

An online questionnaire was created to collect detailed information on the surgical technique used by ACL surgeons in Sweden. The questionnaire was based on the items in the anatomic anterior cruciate ligament reconstruction scoring checklist (AARSC) $[6,26]$. The checklist allows for calculation of an "anatomic score" with a total of 19 points. The items were translated into Swedish by a professional language editor.

The questionnaire was launched via an online survey (http://lulab.orthop.gu.se/korsbandskirurgi) in January 2015. The 175 surgeons registered in the National Register as of 31 December, 2014 were asked via email to participate. Non-responders were sent three reminders. Data collection ended on 30 April, 2015. For each item in the questionnaire, the surgeon was asked to specify whether they consistently "Always" or "Never" used the surgical technique in question, and whether they still used the technique today. If the surgeon had adapted their surgical technique to subsequently include the item in question, or whether there was uncertainty as to when this change took place, the surgeon had the option to specify by answering the questions: "Never performed until year" and "Always performed after year", with a specific year chosen from a drop-down menu. This was repeated for items 1-17 in the questionnaire. This resulted in a time interval where it was possible to identify the surgical technique(s) used by each surgeon who responded, as well as the corresponding patients on which these techniques were implemented.

Groups were created using combinations of eight items selected from the AARSC. These eight items were selected by the authors with the aim of forming groups that were considered reflect the surgical techniques utilized during the various stages of evolution of ACL reconstruction seen in recent years. This created comparable groups of adequate size. Each group had a mandatory "Yes" or "No" answer requirement for certain items that subsequently identified that particular group (Table 1). For example, the group "TP-anatomic" was identified by "Yes" answers to "transportal drilling of the femoral ACL tunnel(s)", "placing the femoral tunnel(s) in the femoral ACL insertion site" and "placing the tibial tunnel(s) in the tibial ACL insertion site". No pre-specified answer requirements were assigned to the remaining five items for that particular group; to these items surgeons could respond with either "Yes" or "No". 
Fig. 1 Flow diagram of inclusion and exclusion criteria

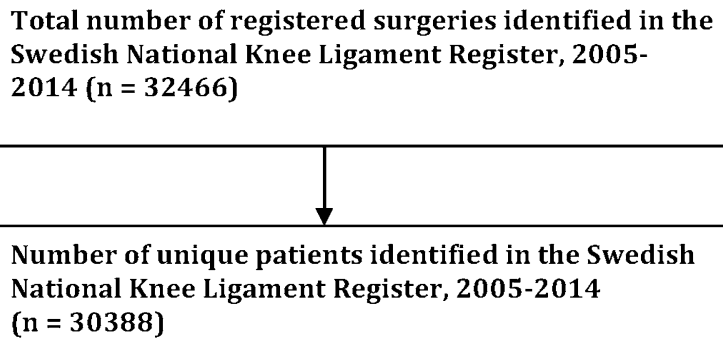

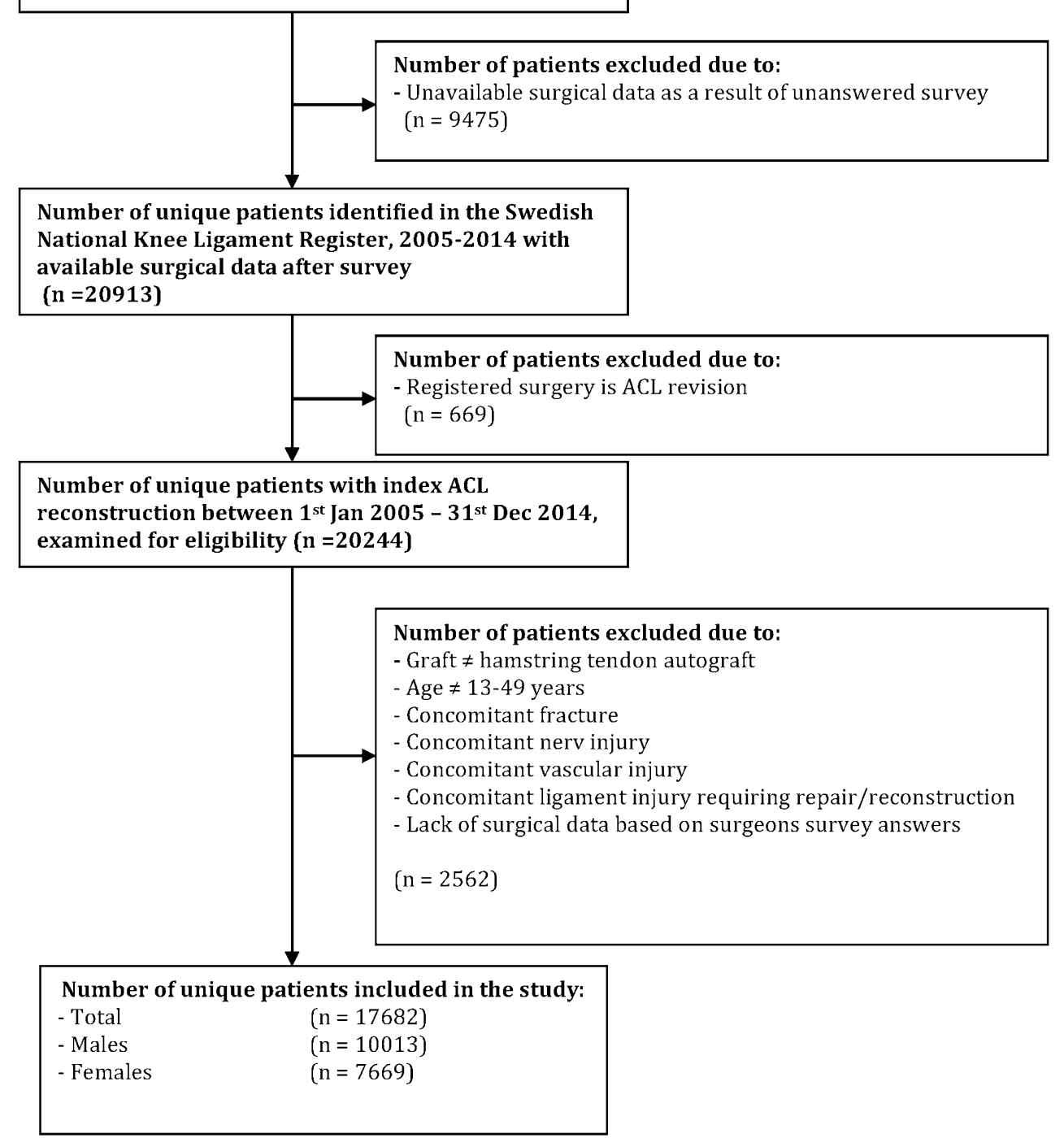

All group comparisons were made to a reference group named "TP-reference" (Table 1). The study end-point was ACL revision surgery, defined as replacement of a primary ACL reconstruction. The Regional Ethical Review Board in Gothenburg, Sweden, approved this study (Ref: 760-14).

\section{Statistical analysis}

Tables and diagrams were generated using Microsoft Excel for Mac (Version 14.5.9, Microsoft Corp, Redmond, WA, USA). A statistician assigned to the Swedish National Knee
Ligament Register performed all statistical analyses. Statistical analysis was performed in IBM SPSS statistics (Version 23.0, IBM Corp, Armonk, NY, USA). Kaplan-Meier survival analysis was used to assess the cumulative graft survival rates. Statistical significance was defined as a $95 \%$ CI for hazard ratios not including 1.0 and a $P$ value $<0.05$. Multivariate analysis adjusted for possible confounding factors (age, patient sex, concomitant injury to menisci or cartilage) was analysed using a Cox regression model and expressed as hazard ratios and $95 \%$ confidence intervals (CI). The assumption of proportional hazards was assessed by use of $\log -\log$ plots. 


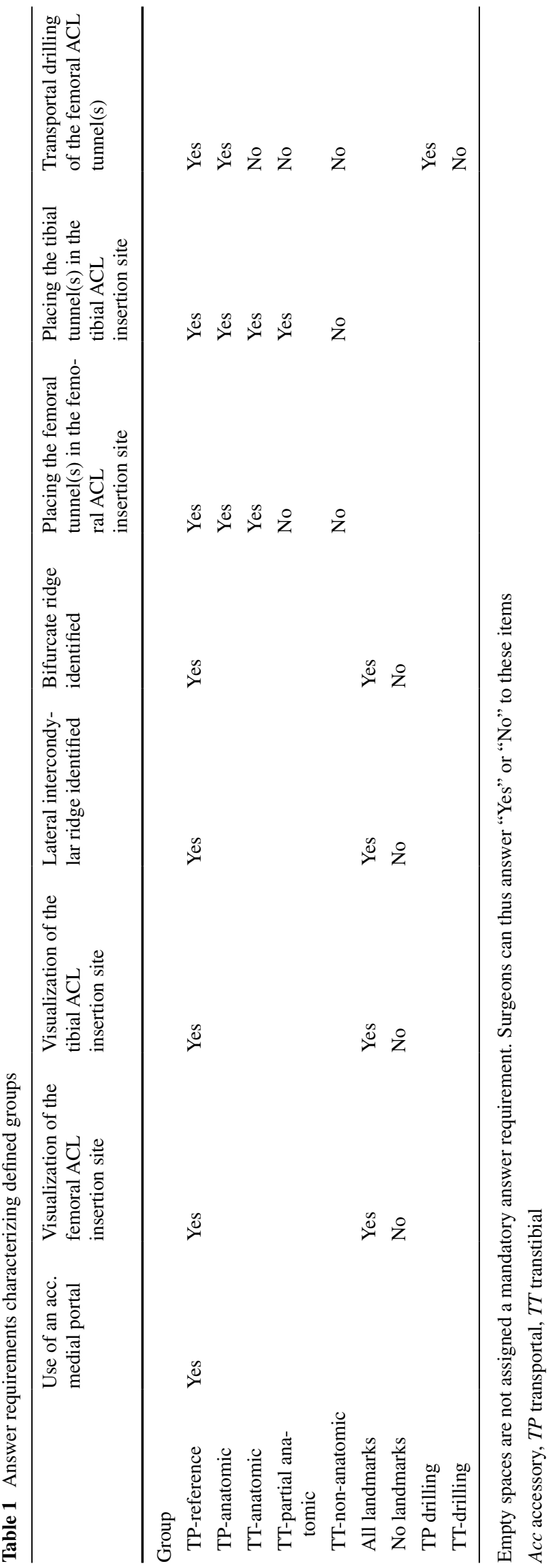

\section{Results}

A total of 108 surgeons completed the questionnaire corresponding to a $61.7 \%$ response rate. Seven surgeons declined to participate citing inability to accurately complete the questionnaire due to low or absent volume of ACL reconstructions (Fig. 2). Current adoption of the individual items of the AARSC is illustrated in Fig. 3. None of the respondents reported using the highest level of documentation according to the AARSC (yielding 2 points), namely 3D MRI, 3D CT or navigation. The mean nationwide AARSC score based on the questionnaire answers was 13.8 points (Fig. 4).

A total of 17,682 patients were included in the study [ $n=10,013$ males $(56.6 \%)$ and 7669 females (43.4\%)] (Fig. 1; Table 2). The median age at index surgery was 24 years (range 13-49 years). Five patients suffered a contralateral ACL injury and were excluded from the analysis. A total of $552(3.1 \%)$ patients underwent ACL revision surgery $[n=296$ males $(53.6 \%)$ and 256 females (46.4\%)] (Table 3).

\section{Patient sex}

Patient sex was not associated with the risk of revision [HR 1.128 (95\% CI 0.954-1.333); n.s.] (Fig. 5; Table 3).

\section{Patient age}

The oldest age group (36-49 years) was set as the reference group, and hence, all subsequent comparisons were made to that group (Tables 2, 3). The youngest age group (1315 years) showed a 5.259-times increased risk of revision compared with the reference age group [HR 5.259 (95\% CI 3.532-7.833); $P<0.001]$. The age group 31-35 years was not associated with the risk of revision compared with the reference group [HR 1.527 (95\% CI 0.941-2.479); n.s.] (Fig. 6; Table 3). When stratifying the cohort into two groups and comparing patients 13-25 years of age ( $n=10,042)$ with those $26-49$ years of age $(n=7640)$, the younger age group showed a 3.19-fold significantly increased risk of revision compared with the older age group [HR 3.19 (95\% CI 2.587-3.934); $P<0.001$ ].

\section{Meniscus injury and cartilage injury}

Meniscus injury seen at index surgery was not associated with the risk of revision [HR 0.994 (95\% CI 0.840-1.176); n.s.] (Table 3). A decreased risk of revision was seen amongst patients with cartilage injury present at index surgery [HR 0.720 (95\% CI $0.587-0.883) ; P=0.002$ ] (Table 3 ). The combined effect of meniscus and/or cartilage injury observed at index surgery was not an associated with the risk of revision [HR 0.853 (95\% CI 0.722-1.088); n.s.] (Table 3; Figs. 7, 8). 
Fig. 2 Flow diagram of questionnaire distribution

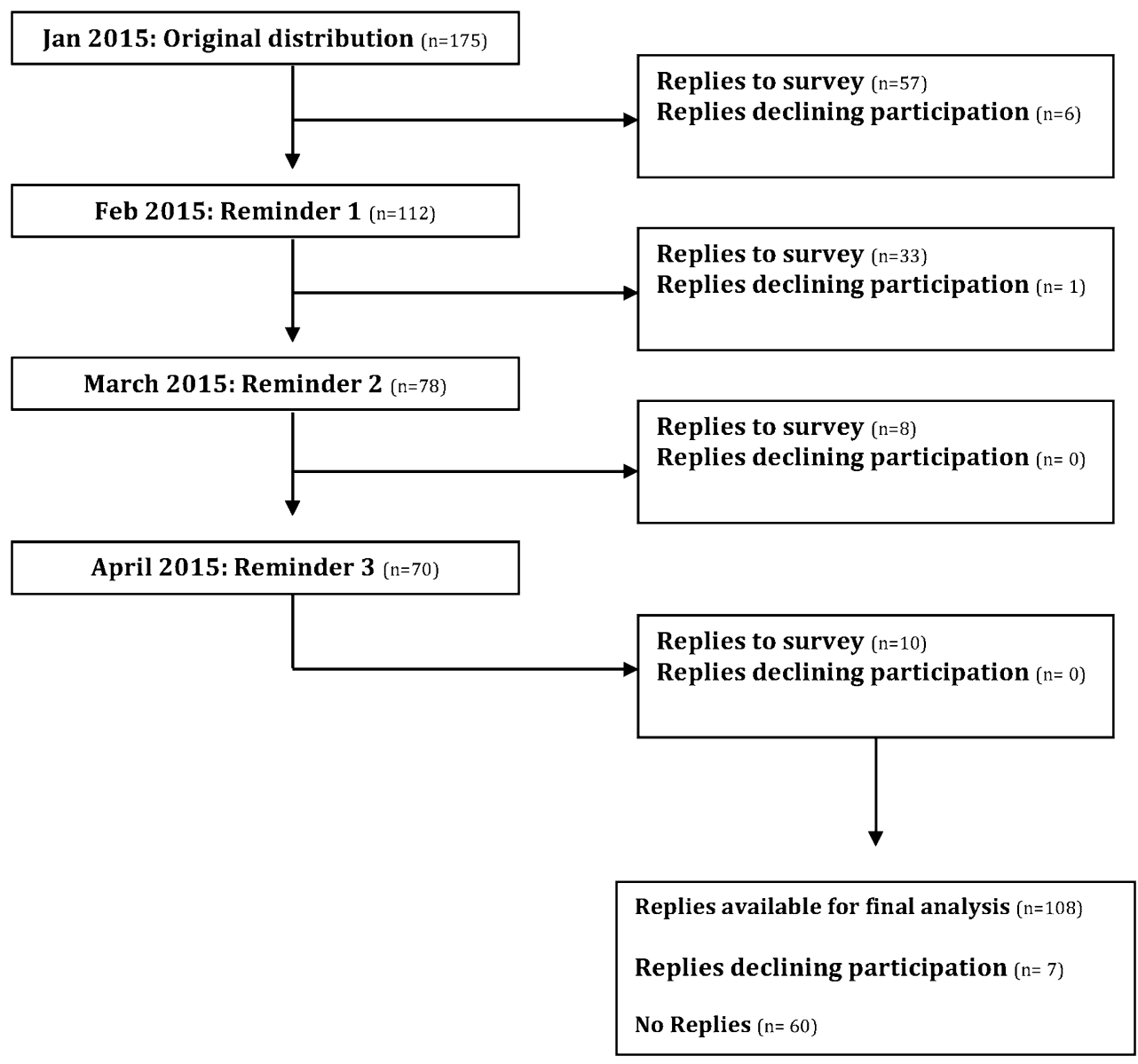

\section{Surgical technique}

Patients in the TT-non-anatomic group had the lowest risk of revision surgery compared with the TP-reference group [HR 0.694 (95\% CI 0.490-0.984); $P=0.041$ ]. In contrast, the TP-anatomic group had a higher risk of revision surgery compared with the TP-reference group [HR 1.310 (95\% CI $1.047-1.640) ; P=0.018]$. There were no significant differences in risk of revision surgery between the TT-anatomic and TT-partial anatomic groups compared with the TP-reference group (Fig. 9; Table 4).

\section{Landmarks}

Visualizing all landmarks was not associated with the risk of revision surgery [HR 1.392 (95\% CI 0.931-2.081); n.s.] (Table 4).

\section{Drilling}

Transportal femoral bone tunnel drilling was associated with an increased risk of revision surgery compared with transtibial femoral bone tunnel drilling [HR 1.399 (95\% CI 1.163-1.682); $P<0.001$ ] (Fig. 10; Table 4).

\section{Discussion}

The most important finding of the present study was that the anatomic reference group, comprised of eight essential AARSC items, had a lower risk of revision surgery compared with anatomic bone tunnel placement via transportal drilling. Non-anatomic bone tunnel placement via transtibial drilling resulted in lowest risk of revision surgery. The mean AARSC score based on the respondent's answers was 13.84, which reflects a promising trend that surgeons are adopting more anatomic techniques.

\section{Surgical technique}

\section{Groups}

The patients were divided into separate groups based on the surgical techniques adopted by the orthopaedic surgeon. This created a unique possibility to compare different surgical techniques with each other. Patients in the TT-nonanatomic group, with mandatory placement of the graft outside the femoral and tibial footprints, had the lowest risk of revision compared with all other groups. Since these grafts are placed non-anatomically, the forces applied to 


$$
\equiv \text { YES (\%) } \equiv \text { NO (\%) }
$$

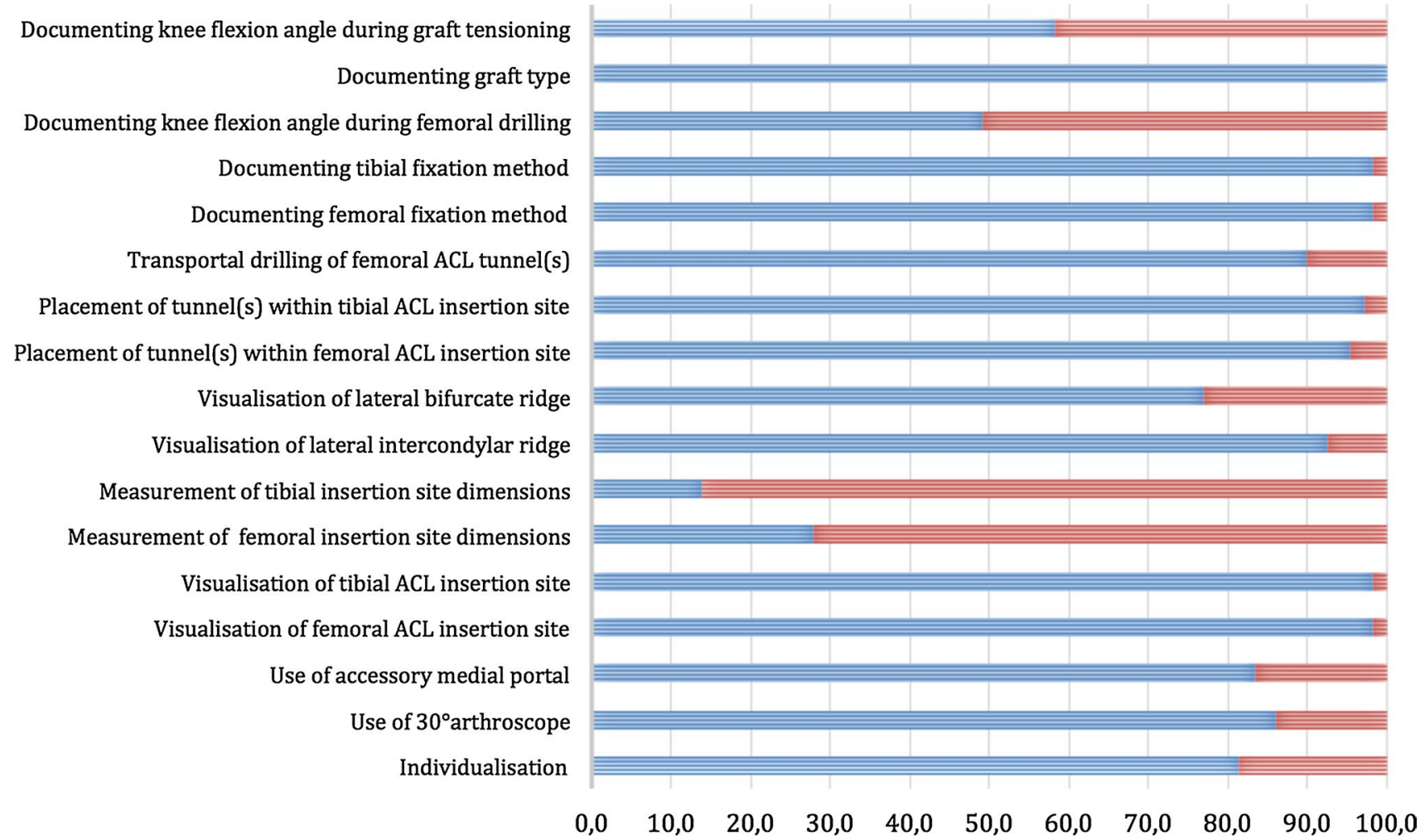

Fig. 3 Current national frequency of use of surgical variable amongst questionnaire respondents

Fig. 4 Mean AARSC score based on respondents questionnaire answers

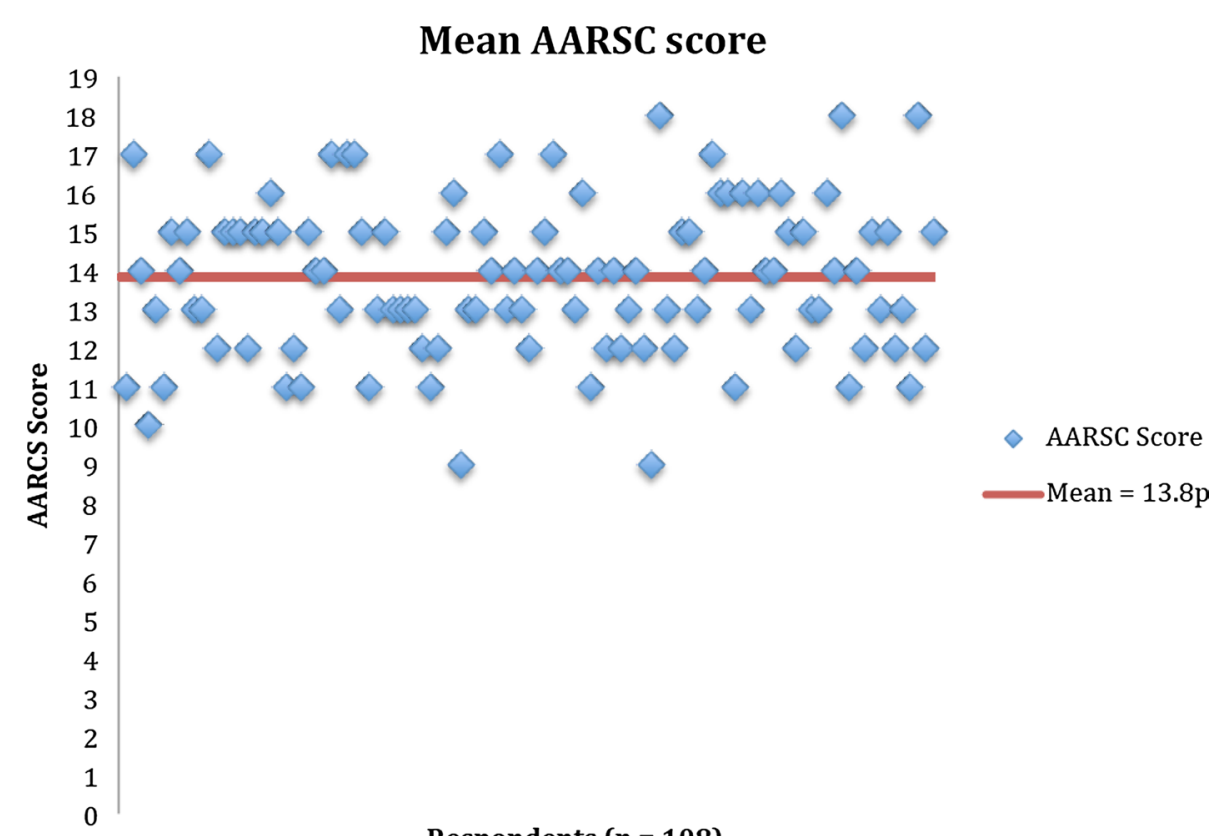

Respondents $(\mathrm{n}=\mathbf{1 0 8})$ the grafts are possibly lower [3, 11, 16, 29]. Furthermore, incorrect placement of a graft will likely result in a residual rotational laxity of the knee, thus creating persisting instability [7, 20]. Such instability may lead to adaptation of patient behaviour and activity level, decreasing the risk of a re-rupture of the graft. In addition to this, the residual 
Table 2 Description of baseline cohort

\begin{tabular}{|c|c|c|}
\hline & \multicolumn{2}{|c|}{ Cohort $(n=17,682)$} \\
\hline & $\%$ & $N$ \\
\hline \multicolumn{3}{|l|}{ Patient sex } \\
\hline Male & 56.6 & 10,01 \\
\hline Female & 43.4 & 7669 \\
\hline \multicolumn{3}{|c|}{ Age at index ACL reconstruction } \\
\hline $13-15$ years & 7.4 & 1300 \\
\hline $16-20$ years & 28.7 & 5075 \\
\hline $21-25$ years & 20.7 & 3667 \\
\hline 26-30 years & 14.2 & 2513 \\
\hline $31-35$ years & 10.0 & 1777 \\
\hline $36-49$ years & 18.9 & 3350 \\
\hline \multicolumn{3}{|c|}{ Concomitant MCL injury at index surgery } \\
\hline Yes & 2.4 & 425 \\
\hline No & 97.6 & 17,257 \\
\hline \multicolumn{3}{|c|}{ Concomitant LCL injury at index surgery } \\
\hline Yes & 0.6 & \\
\hline No & 99.4 & 17,582 \\
\hline \multicolumn{3}{|c|}{ Meniscus injury present (medial and/or lateral) at index surgery } \\
\hline Yes & 43.8 & 7743 \\
\hline No & 56.2 & 9939 \\
\hline \multicolumn{3}{|c|}{ Cartilage injury present at index surgery } \\
\hline Yes & 26.0 & 4598 \\
\hline No & 74.0 & 13,084 \\
\hline \multicolumn{3}{|c|}{ Meniscus and/or cartilage injury at index surgery } \\
\hline Yes & 54.8 & 9685 \\
\hline No & 45.2 & 7997 \\
\hline
\end{tabular}

$A C L$ anterior cruciate ligament, $L C L$ lateral collateral ligament, $M C L$ medial collateral ligament

laxity may lead to increased osteoarthritic changes that in turn, with time, stabilize the knee, reducing the need for revision surgery.

A unique finding in this study was that the reference group with a more complete anatomic reconstruction technique, with the visualization of both footprints, identification of the ridges and anatomic tunnel placement via transportal drilling utilizing an accessory medial portal, showed a decreased risk of revision compared with transportal drilling and anatomic tunnel placement on the femur and tibia. Surgeons performing reconstructions according to the TP-reference group may be more experienced, performing larger volumes of reconstructions per year, possibly explaining the difference in risk of revision surgery. Furthermore, the "TP-reference" group produced similar revision risks compared with patients who underwent reconstruction with transtibial bone tunnel drilling,
Table 3 Patient sex, age and concomitant injury and risk of revision ACL surgery

\begin{tabular}{|c|c|c|c|c|c|}
\hline & \multicolumn{5}{|c|}{ Revision cohort $(n=552)$} \\
\hline & $\%$ & $N$ & Hazard rate & $95 \% \mathrm{CI}$ & $P$ value \\
\hline \multicolumn{6}{|l|}{ Patient sex } \\
\hline Male $^{\mathrm{a}}$ & 53.6 & 296 & 1.128 & $0.954-1.333$ & n.s. \\
\hline Female & 46.4 & 256 & & & \\
\hline \multicolumn{6}{|c|}{ Age at index ACL reconstruction } \\
\hline $13-15$ years & 13.4 & 74 & 5.259 & $3.532-7.833$ & $<0.001$ \\
\hline $16-20$ years & 45.7 & 252 & 4.675 & $3.297-6.628$ & $<0.001$ \\
\hline $21-25$ years & 21.2 & 117 & 3.131 & $2.155-4.548$ & $<0.001$ \\
\hline $26-30$ years & 7.8 & 43 & 1.590 & $1.021-2.476$ & 0.040 \\
\hline $31-35$ years & 5.4 & 30 & 1.527 & $0.941-2.479$ & n.s. \\
\hline $36-49$ years $^{\mathrm{a}}$ & 6.5 & 36 & & & \\
\hline \multicolumn{6}{|c|}{ Meniscus injury present (medial and/or lateral) at index surgery } \\
\hline Yes & 43.1 & 238 & 0.994 & $0.840-1.176$ & n.s. \\
\hline $\mathrm{No}^{\mathrm{a}}$ & 56.9 & 314 & & & \\
\hline \multicolumn{6}{|c|}{ Cartilage injury present at index surgery } \\
\hline Yes & 21.2 & 117 & 0.720 & $0.587-0.883$ & 0.002 \\
\hline $\mathrm{No}^{\mathrm{a}}$ & 78.8 & 435 & & & \\
\hline
\end{tabular}

$A C L$ anterior cruciate ligament, $C I$ confidence interval

${ }^{\text {a }}$ Reference group

regardless of the actual graft placement on the femur (TTpartial anatomic). This is also a novel finding revealing that anatomic reconstruction is not inferior to TT femoral drilling techniques. Altogether, this study shows that simply grouping techniques into transtibial and transportal drilling, without further surgical data is not enough and clearly creates a confounding effect that is not adjusted for.

Interestingly, patients in the TP-anatomic group had the highest risk of revision surgery compared with all other groups. An inherent learning curve as well as increased graft forces are two of many factors that have been proposed as reasons for the increased revision frequency. Both seem logical and anatomic placement of the graft has shown less residual laxity which in turn correlates to increased forces on the graft $[3,11,16,29]$. Studies have yet to show the effects of a learning curve in anatomic reconstruction.

Its is noteworthy that looking solely at crude revisions rates between the surgical groups and drilling techniques, in certain cases revealed results in contradiction to the adjusted hazard rates. This, however, can be explained by the difference in detection times between the two groups being compared, and this is subsequently accounted for during the Cox regression analysis. 


\section{Drilling}

Femoral tunnel drilling through an accessory portal was associated with an increase in revision surgery. Rahr-Wagner et al. [23] have previously reported similar findings.
However, when more surgical factors are accounted for, this study shows that the drilling technique is a confounding factor. First, patients in the TT-non-anatomic group had the lowest risk of revision. These patients would also be categorized only according to their drilling technique and
Fig. 5 Kaplan-Meier survival function of patient sex and revision ACL surgery

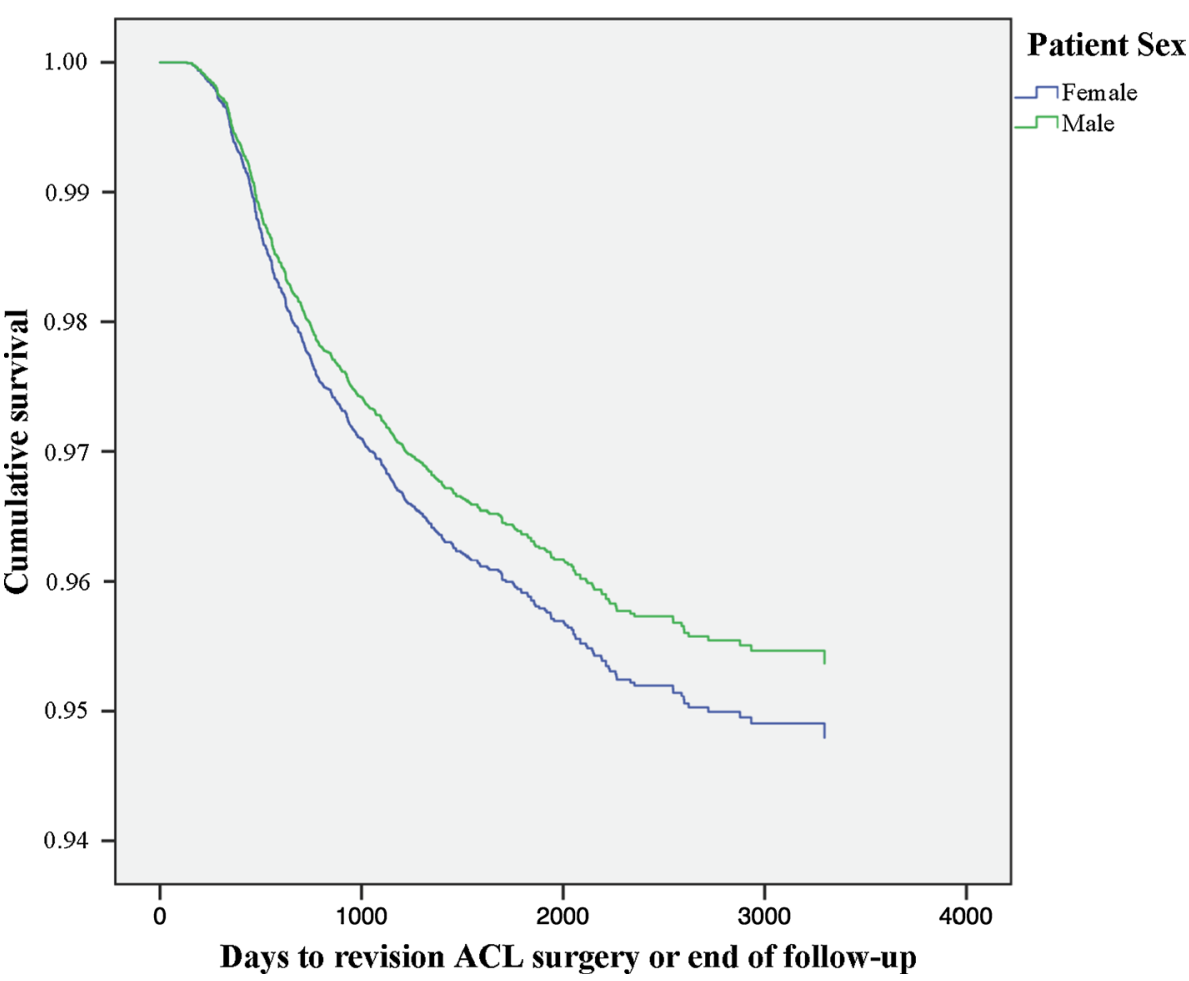

Fig. 6 Kaplan-Meier survival function of age at index surgery and revision ACL surgery

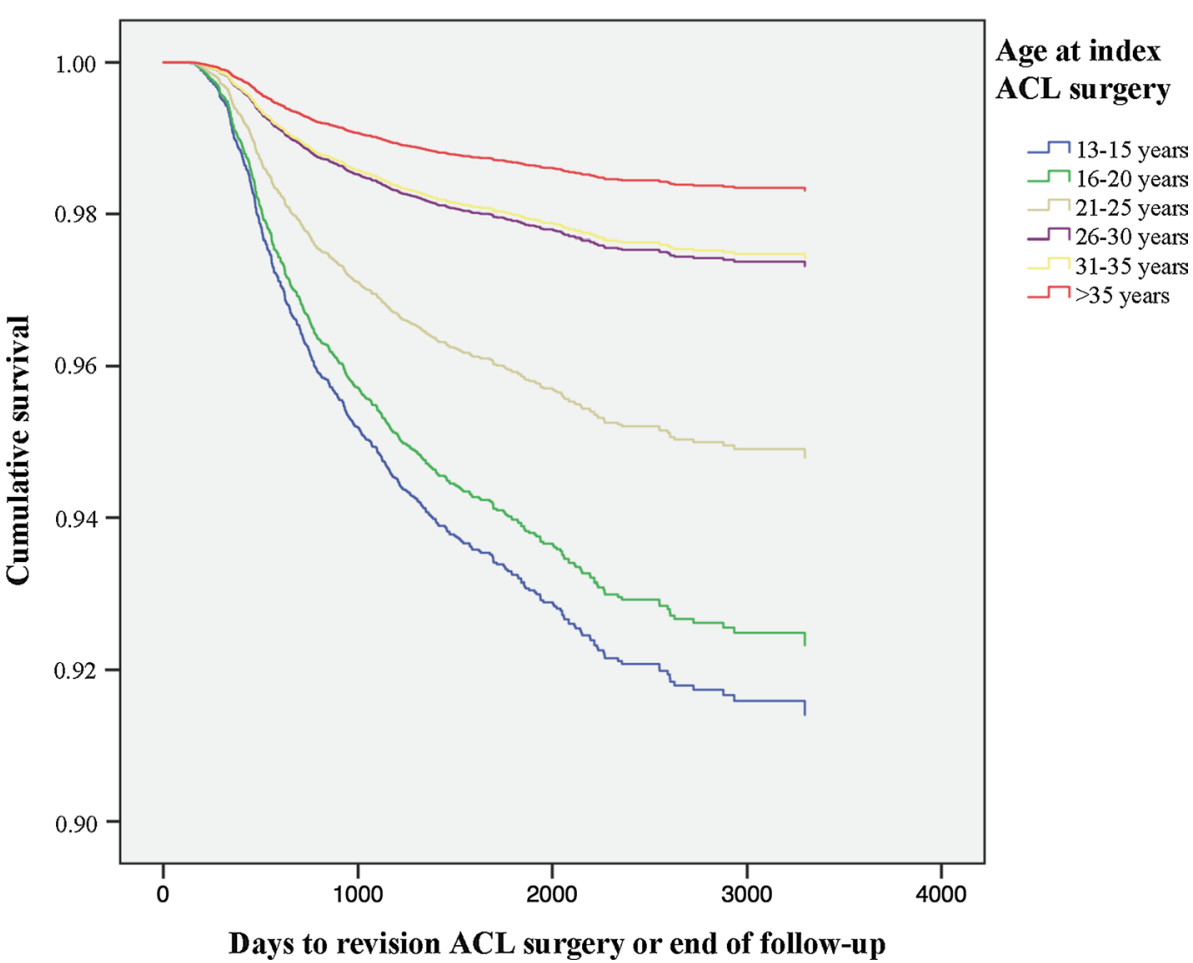


Fig. 7 Kaplan-Meier survival function of meniscus injury and revision ACL surgery

Fig. 8 Kaplan-Meier survival function of cartilage injury and revision ACL surgery
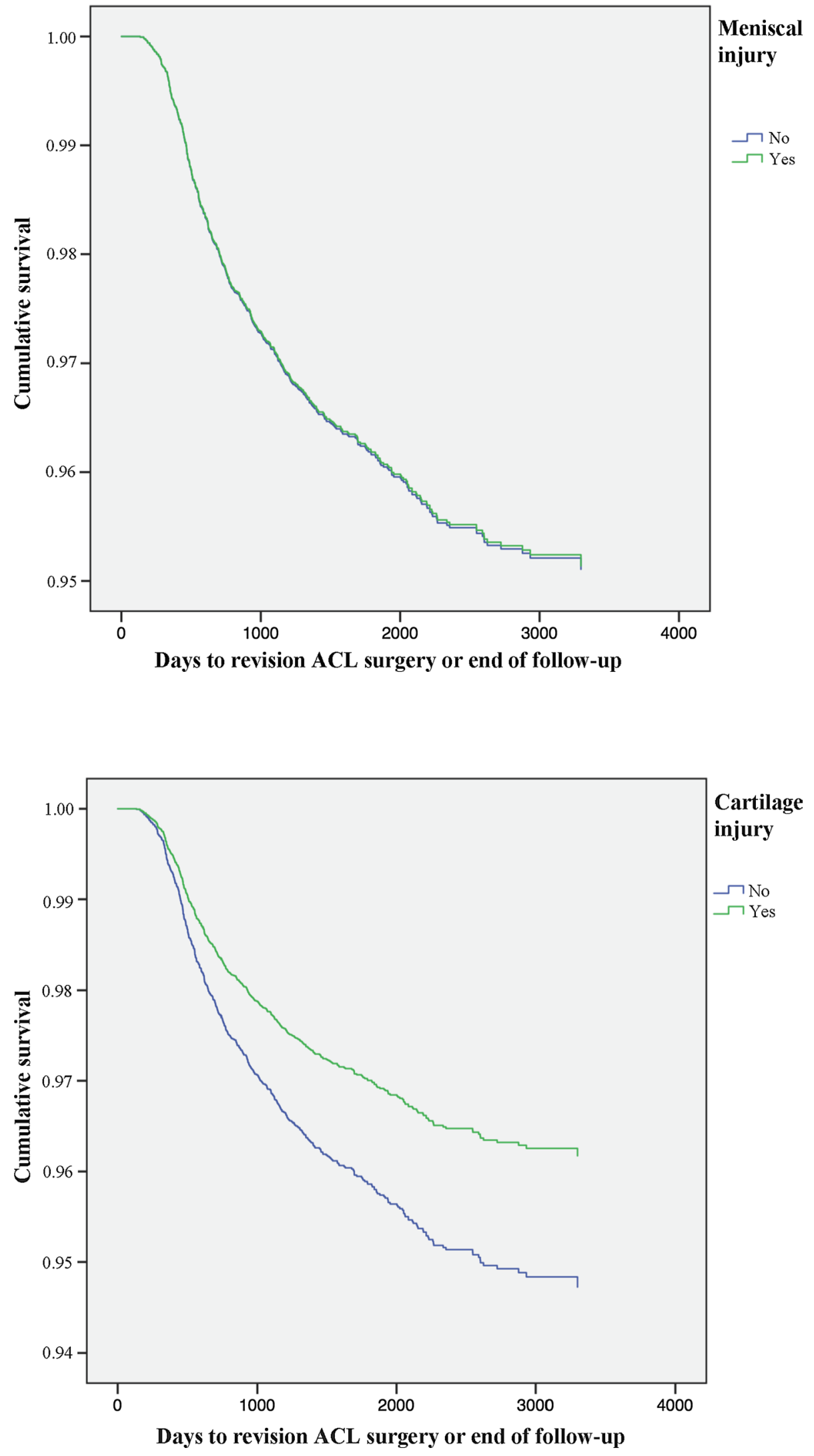
Fig. 9 Kaplan-Meier survival function of surgical group and revision ACL surgery

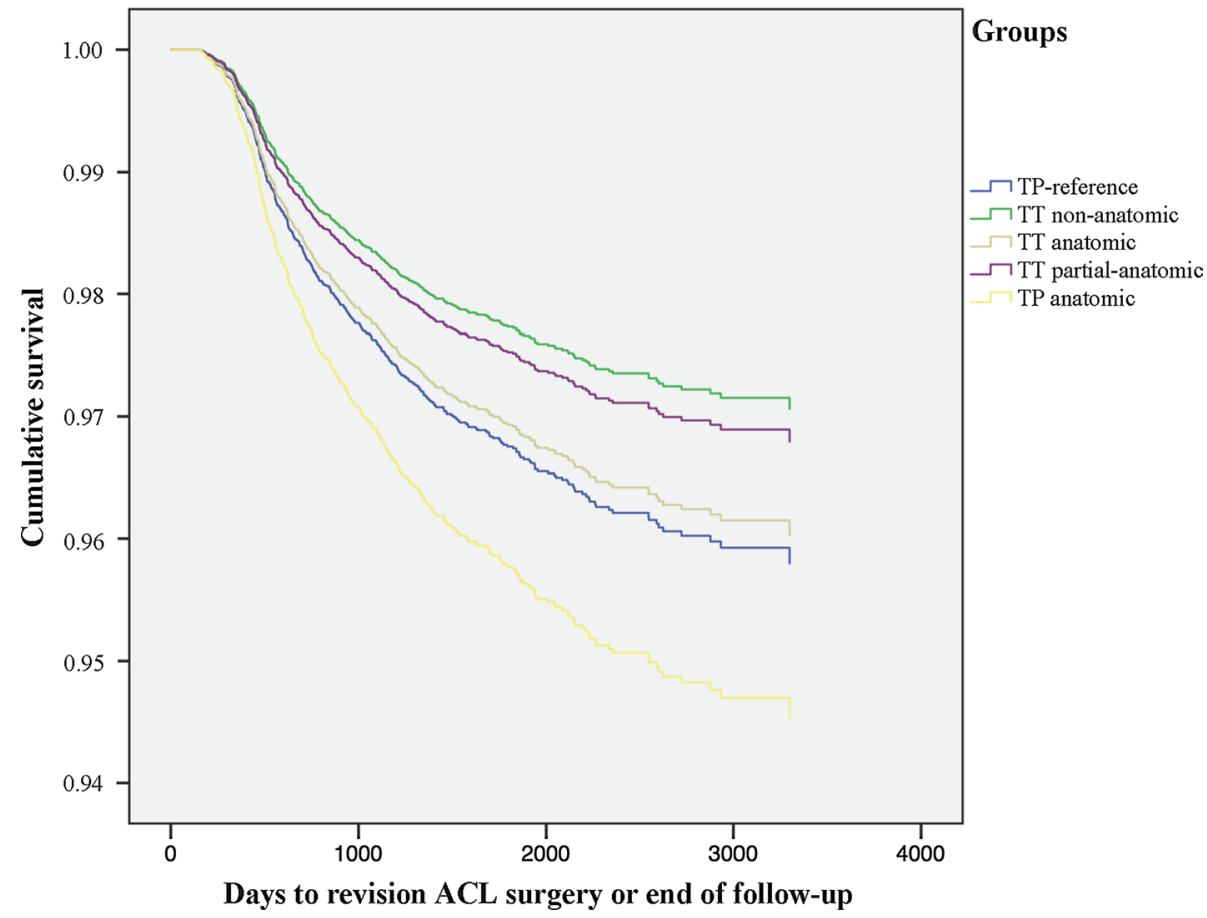

potentially skewing the results. Second, the TP-reference group revealed similar results compared with the TT-partial-anatomic and TT-anatomic groups. This suggests that modern anatomic ACL surgery produces equivalent results compared with modern transtibial techniques. A scientific comparison should therefore always include detailed surgical data, preferably items from the AARSC checklist, as these might act as important confounding factors. Finally, these results may indicate a learning curve is inherent to anatomic reconstruction entailing that reconstruction techniques used during the dawn of anatomic ACL reconstruction are possibly not equivalent to today's modern TP-reference group, making comparisons between patients operated during these separate time periods difficult.

\section{Patient sex}

Secondary findings of this study found that patient sex did not influence risk of revision. These findings are similar to current literature on the subject [1].

\section{Patient age}

Younger age was associated with an increased risk of revision with a more than fivefold increased risk of revision in the group 13-25 years and more than fourfold increased risk of revision in the group 16-20 years compared with older patients (36-49 years). This may be a result of younger patients having a higher activity level both pre-injury and subsequently post-operatively, therefore, exposing the graft to deleterious loads. It may also be a consequence of a lack of compliance to post-operative rehabilitation regimes and restrictions, resulting from an over-eagerness to return to activity. It is also possible that younger patients have higher demands and expectations on the reconstruction and opt for revision surgery to a greater extent. There is a possibility that other biological factors play a part too; however, this is not confirmed in current literature. The association between younger patient age and increased risk of graft failure and revision surgery is well established in current literature [2, $9,14,17,18,22,27,30]$.

\section{Meniscal and cartilage injuries}

Cartilage injury at the time of index reconstruction was a factor associated with decreased risk of revision surgery. Meniscal injuries were not found to influence risk of revision surgery. Although not fully understood, several reasons have been proposed [1]. Cartilage and meniscal injury may be indicative of a significant initial knee trauma, possibly entailing a reduction in activity level in those patients post-operatively. In addition, the presence of concomitant injuries may entail extended rehabilitation protocols, both pre- and post-operatively, which possibly could possibly be beneficial in terms of graft failure and revision. A consequence of this could also be a prolonged time between 
Table 4 Surgical technique and risk of revision ACL surgery

\begin{tabular}{|c|c|c|c|c|c|c|c|c|c|}
\hline \multirow{2}{*}{\multicolumn{4}{|c|}{ Group }} & \multicolumn{3}{|l|}{ HR } & \multicolumn{3}{|c|}{ ADJUSTED HR ${ }^{\mathrm{a}}$} \\
\hline & & & & \multirow[t]{2}{*}{ HR } & \multirow[t]{2}{*}{$95 \% \mathrm{CI}$} & \multirow[t]{2}{*}{$P$ value } & \multirow[t]{2}{*}{ HR } & \multirow[t]{2}{*}{$95 \% \mathrm{CI}$} & \multirow[t]{2}{*}{$P$ value } \\
\hline Comparison group & No. of events ${ }^{b}$ & Reference group & No. of events ${ }^{b}$ & & & & & & \\
\hline $\begin{array}{l}\text { TT-non-anatomic } \\
(n=1296)\end{array}$ & $n=40$ & $\begin{array}{l}\text { TP-reference } \\
\quad(n=6685)\end{array}$ & $n=162$ & 0.704 & $0.497-0.998$ & 0.049 & 0.694 & $0.490-0.984$ & 0.041 \\
\hline $\begin{array}{r}\text { TT-anatomic } \\
(n=2159)\end{array}$ & $n=77$ & & & 0.942 & $0.717-1.239$ & n.s. & 0.944 & $0.718-1.241$ & n.s. \\
\hline $\begin{array}{l}\text { TT-partial anatomic } \\
(n=1516)\end{array}$ & $n=48$ & & & 0.723 & $0.522-1.001$ & n.s. & 0.759 & $0.548-1.051$ & n.s. \\
\hline $\begin{array}{r}\text { TP-anatomic } \\
(n=4036)\end{array}$ & $n=146$ & & & 1.285 & $1.027-1.607$ & 0.028 & 1.310 & $1.047-1.640$ & 0.018 \\
\hline $\begin{array}{l}\text { All landmarks } \\
(n=9398)\end{array}$ & $n=252$ & $\begin{array}{l}\text { No landmarks } \\
(n=831)\end{array}$ & $n=27$ & 1.387 & $0.928-2.072$ & n.s. & 1.392 & $0.931-2.081$ & n.s. \\
\hline $\begin{array}{l}\text { TP drilling } \\
\qquad(n=12,440)\end{array}$ & $n=380$ & $\begin{array}{l}\text { TT-drilling } \\
\quad(n=5110)\end{array}$ & $n=167$ & 1.390 & $1.157-1.670$ & $<0.001$ & 1.399 & $1.163-1.682$ & $<0.001$ \\
\hline
\end{tabular}

$C I$ confidence interval, $H R$ hazard ratio, TP transportal, TT transtibial

${ }^{a}$ Multivariate Cox regression analysis adjusted for patient sex, patient age and meniscal or chondral injury

${ }^{\mathrm{b}}$ Event $=$ revision ACL surgery

Fig. 10 Kaplan-Meier survival function of femoral drilling technique and revision $\mathrm{ACL}$ surgery

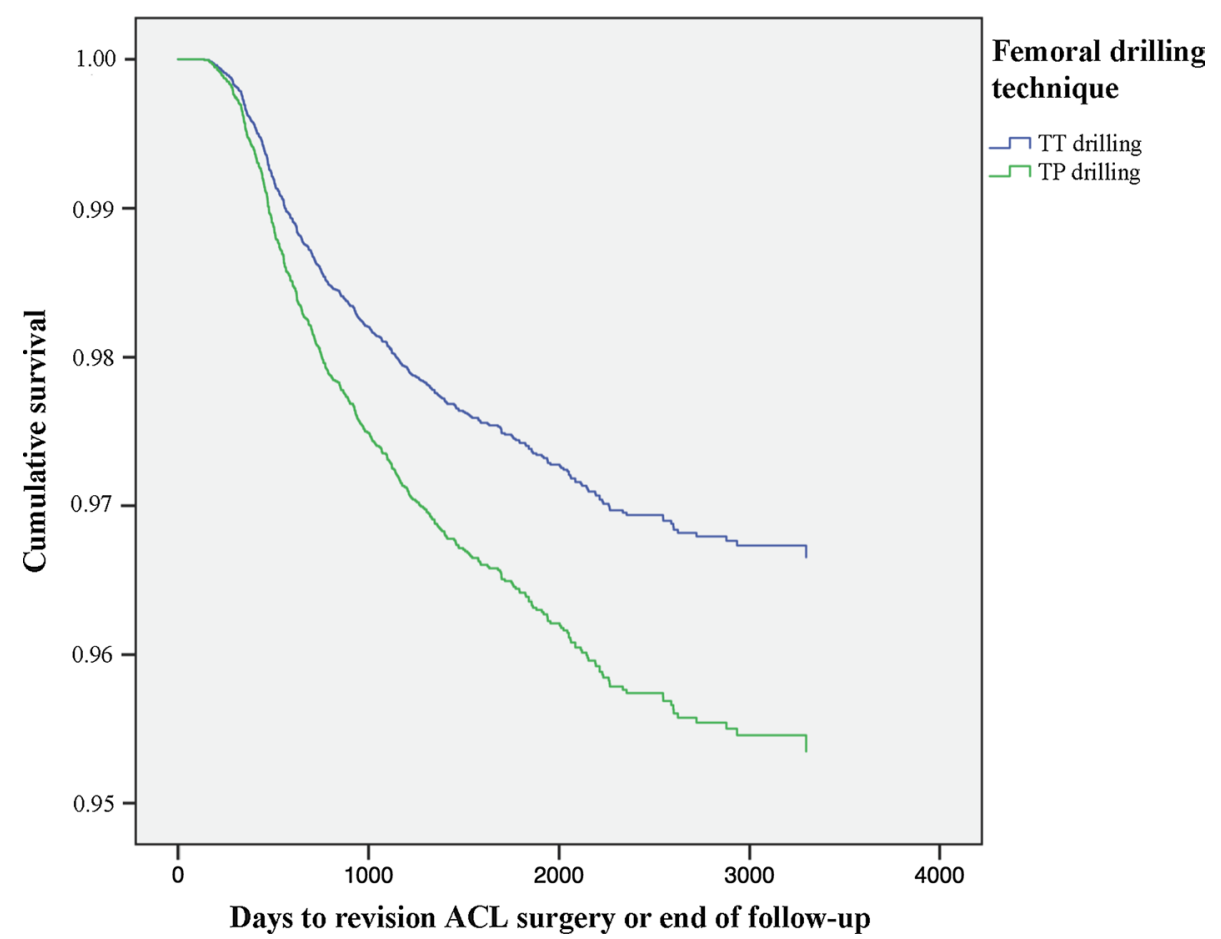

injury and surgery, potentially shifting an eventual revision outside of the scope of this study's follow-up.

\section{Limitations}

An important limitation is that the primary end-point was revision surgery, which fails to identify the total number of graft failures, as not all failures opt to undergo revision surgery. In addition, information on activity level is not available in the register. In this study, a retrospective analysis was performed through an online questionnaire on surgical data, which in turn can entail an element of a recall bias. Assuming honest answers, the surgeon can still erroneously recall dates when a certain technique was adopted. To minimize recall bias, responders were informed to only answer the question 
whether they were sure of the date they adopted or abandoned the surgical technique in question. In addition, responders were asked to only specify years and not months in an attempt to further minimize recall errors. Moreover, all patients that were operated on during time periods when the surgeon was "in-between" surgical techniques were not included. No verification of the surgical techniques utilized by the nonresponders to the questionnaire was undertaken, creating risk of selection bias. The results of this study are only applicable to ACL reconstructions using hamstring grafts. The cause of failure and subsequent revision after ACL surgery and after ACL reconstruction is not solely influenced by the surgical technique used. The present study has adjusted analysis for some of these possible influential factors, but not all of them, and conclusions must be made with this in mind.

\section{Conclusion}

Overall revision rate was low. Non-anatomic bone tunnel placement via transtibial drilling resulted in the lowest risk of revision surgery after ACL reconstruction. The risk of revision surgery increased when using transportal drilling. Performing anatomic ACL reconstruction utilizing eight selected essential items from the AARSC lowered the risk of revision surgery associated with transportal drilling and anatomic bone tunnel placement. Detailed knowledge of surgical technique using the AARSC predicts the risk of ACL revision surgery.

\section{Compliance with ethical standards}

Conflict of interest Desai, Sundemo, Andernord, Alentorn-Geli, Musahl, Fu, Forssblad and Samuelsson declare that they have no conflict of interest.

Funding No outside funding or grants directly related to the research presented in this manuscript. The department of Orthopaedic Surgery from the University of Pittsburgh receives funding from Smith and Nephew to support research related to reconstruction of the ACL.

Ethical approval The Regional Ethical Review Board in Gothenburg, Sweden, approved this study (Ref: 760-14).

Informed consent As this is a study based on data from a register, informed consent statements for patient enrollment is not applicable. No such informed consent statement for surgeon participation in the study through the survey was aquired either.

Open Access This article is distributed under the terms of the Creative Commons Attribution 4.0 International License (http://creativecommons.org/licenses/by/4.0/), which permits unrestricted use, distribution, and reproduction in any medium, provided you give appropriate credit to the original author(s) and the source, provide a link to the Creative Commons license, and indicate if changes were made.

\section{References}

1. Andernord D, Bjornsson H, Petzold M, Eriksson BI, Forssblad M, Karlsson J, Samuelsson K (2014) Surgical predictors of early revision surgery after anterior cruciate ligament reconstruction: results from the Swedish National Knee Ligament Register on 13,102 patients. Am J Sports Med 42:1574-1582

2. Andernord D, Desai N, Bjornsson H, Ylander M, Karlsson J, Samuelsson K (2015) Patient predictors of early revision surgery after anterior cruciate ligament reconstruction: a cohort study of 16,930 patients with 2-year follow-up. Am J Sports Med 43:121-127

3. Araujo PH, Asai S, Pinto M, Protta T, Middleton K, Linde-Rosen M, Irrgang J, Smolinski P, Fu FH (2015) acl graft position affects in situ graft force following ACL reconstruction. J Bone Joint Surg Am 97:1767-1773

4. Ardern CL, Taylor NF, Feller JA, Webster KE (2014) Fifty-five per cent return to competitive sport following anterior cruciate ligament reconstruction surgery: an updated systematic review and meta-analysis including aspects of physical functioning and contextual factors. Br J Sports Med 48:1543-1546

5. Biau DJ, Tournoux C, Katsahian S, Schranz P, Nizard R (2007) ACL reconstruction: a meta-analysis of functional scores. Clin Orthop Relat Res 458:180-187

6. Desai N, Alentorn-Geli E, van Eck CF, Musahl V, Fu FH, Karlsson J, Samuelsson K (2016) A systematic review of single- versus double-bundle ACL reconstruction using the anatomic anterior cruciate ligament reconstruction scoring checklist. Knee Surg Sports Traumatol Arthrosc 24:862-872

7. Driscoll MD, Isabell GP, Conditt MA, Ismaily SK, Jupiter DC, Noble PC, Lowe WR (2012) Comparison of 2 femoral tunnel locations in anatomic single-bundle anterior cruciate ligament reconstruction: a biomechanical study. Arthroscopy 28:1481-1489

8. Duffee A, Magnussen RA, Pedroza AD, Flanigan DC, Kaeding CC, MOON Group (2013) Transtibial ACL femoral tunnel preparation increases odds of repeat ipsilateral knee surgery. J Bone Joint Surg Am 95:2035-2042

9. Faltstrom A, Hagglund M, Magnusson H, Forssblad M, Kvist J (2016) Predictors for additional anterior cruciate ligament reconstruction: data from the Swedish national ACL register. Knee Surg Sports Traumatol Arthrosc 24:885-894

10. George MS, Dunn WR, Spindler KP (2006) Current concepts review: revision anterior cruciate ligament reconstruction. Am J Sports Med 34:2026-2037

11. Kato Y, Ingham SJ, Kramer S, Smolinski P, Saito A, Fu FH (2010) Effect of tunnel position for anatomic single-bundle ACL reconstruction on knee biomechanics in a porcine model. Knee Surg Sports Traumatol Arthrosc 18:2-10

12. Kato Y, Maeyama A, Lertwanich $P$, Wang JH, Ingham SJM, Kramer S, Martins CQA, Smolinski P, Fu FH (2013) Biomechanical comparison of different graft positions for single-bundle anterior cruciate ligament reconstruction. Knee Surg Sports Traumatol Arthrosc 21:816-823

13. Lewis PB, Parameswaran AD, Rue JPH, Bach BR (2008) Systematic review of single-bundle anterior cruciate ligament reconstruction outcomes - a baseline assessment for consideration of double-bundle techniques. Am J Sports Med 36:2028-2036

14. Lind M, Menhert F, Pedersen AB (2012) Incidence and outcome after revision anterior cruciate ligament reconstruction: results from the Danish registry for knee ligament reconstructions. Am J Sports Med 40:1551-1557

15. Loh JC, Fukuda Y, Tsuda E, Steadman RJ, Fu FH, Woo SLY (2003) Knee stability and graft function following anterior cruciate ligament reconstruction: comparison between 11 o'clock and 10 o'clock femoral tunnel placement. Arthroscopy 19:297-304 
16. Lubowitz JH (2014) Anatomic ACL reconstruction produces greater graft length change during knee range-of-motion than transtibial technique. Knee Surg Sports Traumatol Arthrosc 22:1190-1195

17. Magnussen RA, Lawrence JT, West RL, Toth AP, Taylor DC, Garrett WE (2012) Graft size and patient age are predictors of early revision after anterior cruciate ligament reconstruction with hamstring autograft. Arthroscopy 28:526-531

18. Maletis GB, Chen J, Inacio MC, Funahashi TT (2016) Agerelated risk factors for revision anterior cruciate ligament reconstruction: a cohort study of 21,304 patients from the Kaiser Permanente Anterior Cruciate Ligament Registry. Am J Sports Med 44:331-336

19. Marchant BG, Noyes FR, Barber-Westin SD, Fleckenstein C (2010) Prevalence of nonanatomical graft placement in a series of failed anterior cruciate ligament reconstructions. Am J Sports Med 38:1987-1996

20. Musahl V, Plakseychuk A, VanScyoc A, Sasaki T, Debski RE, McMahon PJ, Fu FH (2005) Varying femoral tunnels between the anatomical footprint and isometric positions-effect on kinematics of the anterior cruciate ligament-reconstructed knee. Am J Sports Med 33:712-718

21. Oiestad BE, Holm I, Aune AK, Gunderson R, Myklebust G, Engebretsen L, Fosdahl MA, Risberg MA (2010) Knee function and prevalence of knee osteoarthritis after anterior cruciate ligament reconstruction a prospective study with 10 to 15 years of follow-up. Am J Sports Med 38:2201-2210

22. Pullen WM, Bryant B, Gaskill T, Sicignano N, Evans AM, DeMaio M (2016) Predictors of revision surgery after anterior cruciate ligament reconstruction. Am J Sports Med. doi:10.1177/0363546516660062

23. Rahr-Wagner L, Thillemann TM, Pedersen AB, Lind MC (2013) Increased risk of revision after anteromedial compared with transtibial drilling of the femoral tunnel during primary anterior cruciate ligament reconstruction: results from the Danish Knee Ligament Reconstruction Register. Arthroscopy 29:98-105
24. Stevenson WW, Johnson DL (2007) "Vertical grafts": a common reason for functional failure after ACL reconstruction. Orthopedics 30:206-209

25. Tashman S, Collon D, Anderson K, Kolowich P, Anderst W (2004) Abnormal rotational knee motion during running after anterior cruciate ligament reconstruction. Am J Sports Med 32:975-983

26. Van Eck CF, Gravare-Silbernagel K, Samuelsson K, Musahl V, van Dijk CN, Karlsson J, Irrgang JJ, Fu FH (2013) Evidence to support the interpretation and use of the Anatomic Anterior Cruciate Ligament Reconstruction Checklist. J Bone Jt Surg Am 95:e153

27. Webster KE, Feller JA, Leigh WB, Richmond AK (2014) Younger patients are at increased risk for graft rupture and contralateral injury after anterior cruciate ligament reconstruction. Am J Sports Med 42:641-647

28. Wright RW, Huston LJ, Spindler KP, Dunn WR, Haas AK, Allen CR, Cooper DE, DeBerardino TM, Lantz BB, Mann BJ, Stuart MJ (2010) Descriptive epidemiology of the Multicenter ACL Revision Study (MARS) cohort. Am J Sports Med 38:1979-1986

29. Xu Y, Liu J, Kramer S, Martins C, Kato Y, Linde-Rosen M, Smolinski P, Fu FH (2011) Comparison of in situ forces and knee kinematics in anteromedial and high anteromedial bundle augmentation for partially ruptured anterior cruciate ligament. Am J Sports Med 39:272-278

30. Yabroudi MA, Bjornsson H, Lynch AD, Muller B, Samuelsson K, Tarabichi M, Karlsson J, Fu FH, Harner CD, Irrgang JJ (2016) Predictors of revision surgery after primary anterior cruciate ligament reconstruction. Orthop J Sports Med. doi: $10.1177 / 2325967116666039$

31. Yamamoto Y, Hsu WH, Woo SLY, Van Scyoc AH, Takakura Y, Debski RE (2004) Knee stability and graft function after anterior cruciate ligament reconstruction-a comparison of a lateral and an anatomical femoral tunnel placement. Am J Sports Med $32: 1825-1832$ 